\title{
An Investigation of Chinese University Students' Foreign Language Anxiety and English Learning Motivation
}

\author{
Meihua Liu ${ }^{1} \&$ Xiaoming Zhang ${ }^{2}$ \\ ${ }^{1}$ Department of Foreign Languages and Literatures, Tsinghua University, Beijing, 100084, China \\ 2 The Foreign Languages College, Donghua University, Shanghai, China \\ Correspondence: Meihua Liu, Department of Foreign Languages and Literatures, Tsinghua University, Beijing, \\ 100084, China. Tel: 86-10-62772459. E-mail: ellenlmh@yahoo.com
}

Received: February 17, 2013

Accepted: March 10, 2013

Online Published: March 21, 2013

doi:10.5430/elr.v2n1p1

URL: http://dx.doi.org/10.5430/elr.v2n1p1

\begin{abstract}
The present paper reports on the findings of a study on the general patterns of Chinese university students' foreign language learning anxiety and motivation and their relationships to the students' performance in English. Analyses of 1697 questionnaires revealed that 1) the whole sample, as well as male and female students, reported a medium or even low level of foreign language anxiety and a moderate or even high level of English learning motivation; 2) more than $60 \%$ of the respondents reported to be at the low level of foreign language anxiety but at the mid level of English learning motivation. And the differences among students of low-, mid-, and high-level foreign language anxiety and English learning motivation were all statistically significant; 3) the students' foreign language anxiety and English learning motivation were significantly correlated with each another, and the students' performance in English; and 4) external motivation, intrinsic motivation, test anxiety, motivation intensity, academic achievement, personal development and going abroad were powerful predictors of the students' performance in English.
\end{abstract}

Keywords: Foreign language anxiety, Motivation, Performance

\section{Introduction}

In recent years, there has been an increasing interest among researchers in the role of affective factors in SLA (Horwitz, Horwitz, \& Cope, 1986; MacIntyre \& Gardner, 1989). Research has shown that foreign language anxiety and motivational factors play an important role in foreign/second language (SL/FL) learning outcomes, academic performance, and student persistence (Csizér \& Dörynei, 2005; Gardner 1985; Kessler, 2010; Ushioda, 2008).

Despite the fact that the relationship between students' foreign language anxiety and motivation and their learning outcomes have been researched in various mainstream educational settings during the past few decades (Dörnyei, 2003; Hao, Liu \& Hao, 2004; Liu \& Huang, 2011), far from enough attention has been paid to the anxiety and motivational characteristics of EFL learners in Mainland China. The interaction of foreign language anxiety and learning motivation has not been adequately researched either. The present research aimed to explore the general patterns of Chinese university students' foreign language learning anxiety and motivation and their relationships to the students' performance in English.

\section{Literature review}

\subsection{Foreign language anxiety}

Language anxiety is a unique type of anxiety that causes worry and negative emotional reactions related to language learning (Horwitz, 2001). As a multidimensional phenomenon (Horwitz et al., 1986; Gardner \& MacIntyre, 1989), foreign language anxiety is "a distinct complex of self-perceptions, beliefs, feelings, and behaviors related to classroom language learning arising from the uniqueness of the language learning process" (Horwitz et al., 1986: 128). According to Horwitz et al. (1986), foreign language anxiety entails three components: communication apprehension, fear of negative evaluation, and test anxiety. People with communication apprehension are shy about communicating with others and have difficulty speaking in public and listening to spoken messages. Test anxiety associates with language anxiety due to unrealistic expectations on language achievement (Horwitz et al., 1986). Similar to test anxiety, students' fear of negative evaluation is more extensive, because evaluation may occur in any evaluative situation, such as group discussions or speaking in front of the classroom, in language classes (MacIntyre, 
1999).

To measure foreign language anxiety, Horwitz et al. (1986) developed an instrument - the 33-item Foreign Language Classroom Anxiety Scale (FLCAS). Since then, research has been flourishing in this area using the scale as the principal data-collection instrument, agreeing on the existence of anxiety in SL/FL classrooms (Ewald, 2007; Kessler, 2010; Tallon, 2009; Yan \& Horwitz, 2008). Though some studies report that anxiety can be facilitating (Frantzen \& Magnan, 2005; Gregersen, 2003; Gregersen \& Horwitz, 2002; Spielmann \& Radnofsky, 2001), findings of most studies have been relatively uniform, indicating a consistently moderate negative relationship between anxiety and SL/FL proficiency/performance (Ewald, 2007; Horwitz, 2001; Liu, 2006b; Liu \& Jackson, 2008; Matsuda \& Gobel, 2004; Mills, Pajare, \& Herron, 2006). For example, Liu and Jackson's (2008) study of 547 Chinese university freshmen revealed that foreign language anxiety was inversely related to the students' self-rated proficiency in and access to English.

Although students with communication apprehension, test anxiety, and fear of negative evaluation are apt to develop language anxiety, they may have different levels of language anxiety due to various variables, such as age, attitudes and motivation, unwillingness to communicate, self-confidence, the learning environment, and gender (Ewald, 2007; Hurd \& Xiao, 2010; Liu, 2006b; Liu \& Jackson, 2008; Mak, 2011; Mills et al., 2006). For example, Elkhafaifi (2005) found that advanced students had lower language anxiety than beginning or intermediate students and that older students who spent more years learning English in school had lower anxiety than younger students.

\subsection{Language learning motivation}

Gardner's social psychological model (Gardner, 1985; Gardner \& Lambert, 1972; Tremblay \& Gardner, 1995) dominated research on language learning motivation from the late 1950s until the 1990s, concentrating on two orientations to motivation: integrative and instrumental motivation. Gardner (1985: 10) defined L2 motivation as "the extent to which the individual works or strives to learn the language because of a desire to do so and the satisfaction experienced in this study" and made a distinction between instrumental and integrative motivation. Instrumental motivation meant studying a language to gain something, such as money or a better job, and integrative motivation expressed students' wish to learn the language in order to become integrated into the target language culture (Gardner, 1985; Gardner \& MacIntyre, 1991). A series of studies has revealed that integrative motivation is the key in predicting students' classroom participation, language proficiency, and persistence in language learning (Csizér \& Dörynei, 2005; Gardner \& MacIntyre, 1991; Liu, 2007).

Beginning in the 1990s, criticisms on this line of research emerged, centering on the components of the motivation construct, the factors affecting motivation and students' own perceptions of their abilities, performances, and possibilities (Crookes \& Schmidt, 1991; Mills, Pajares, \& Herron, 2007; Oxford \& Shearin, 1994; Ushioda, 2008). Drawing on attribution theory, self-determination theory, and social cognitive theory, language learning researchers distinguished intrinsic motivation (namely, feelings of enjoyment and enhancement experienced during the process of language learning) and extrinsic motivation (namely, to learn something as a means to something else) and investigated their relation to other motivational constructs (Dörnyei, 2003; Noels, 2005; Noels, Clément \& Pelletier, 2001; Ryan \& Deci, 2000; Ushioda, 2008; Vandergrift, 2005). Meanwhile, several studies acknowledged the social and contextual influences on individual motivation (Csizér \& Dörnyei, 2005; Kormos \& Csizér, 2008; Kormos, Kiddle \& Csizér, 2011). For example, Wen (1997) found that both intrinsic- and extrinsic-oriented motivations could lead to success to Chinese EFL learners. Warden and Lin (2000) discovered that EFL students in Taiwan appeared to be motivated by requirements rather than either an interest in integration or any clear instrumental yield. Furthermore, some researchers realized that the goal of becoming international should be incorporated into the motivation construct as the world is becoming globalized and English becomes an international language serving as a lingua franca in a globalized world (Jenkins, 2007; Kormos \& Csizér, 2010).

Concurrently, more motivation types are advanced during the process of motivation research (Gao, Zhao, Cheng \& Zhou, 2003a, 2003b, 2004; Liu, 2007; Oxford \& Shearin, 1994). For example, Gao et al.'s (2003a, 2003b, 2004) extensive research involving 2,278 participants from 30 Chinese universities revealed seven motivation types: intrinsic interest, immediate achievement, learning situation, going abroad, social responsibility, individual development, and information medium, which were grouped into three categories - instrumental, cultural and situational by the researchers. More proficient EFL learners reported to have significantly more intrinsic interest; and less proficient EFL learners were significantly more driven by immediate achievement.

In general, these studies are consistent in revealing that motivation contributes to the learning of a SL/FL, that learners high on integrative/intrinsic motivation work harder and learn faster than those who are low, and that learners demonstrate diverse motivation patterns, which is largely supported by numerous empirical studies in 
various contexts (Dörnyei, 2003; MacIntyre \& Gardner, 1991; Liu, 2007; Ushioda, 2008).

\section{Rationale for the Study}

As discussed above, foreign language anxiety and motivation are two important affective variables affecting the learning of English as a SL/FL. Though they have been investigated in various SL/FL contexts, given the complex nature of these two constructs and language learning itself, more efforts are still needed to examine their nature and roles in language learning and acquisition and how they interact with other variables to affect language learning outcomes. It is specially so in Mainland China because of the vast number of FL learners and wide range of learning contexts there. Mainly because English is rarely needed in the daily life in Mainland China, students there might suffer more from anxiety when learning English, especially when speaking the language, and need to be more motivated to learn the language well. Moreover, as reviewed above, the level of anxiety and motivation when learning a SL/FL varies from person to person. Whether a mid-anxious student is significantly more anxious than a low-anxious peer makes a difference in a SL/FL classroom. Thus, it is important to explore the general pattern as well as the within-group pattern of foreign language anxiety and English learning motivation of the selected population. The results will be more revealing and insightful to the practical teaching and learning of a SL/FL in classrooms. For these reasons, the present research aimed to explore the general patterns of Chinese university students' foreign language learning anxiety and motivation and their relationships to the students' performance in English. The following research questions are of particular interest:

(1) What are the general patterns of Chinese university students' foreign language anxiety and English learning motivation?

(2) How does the students' foreign language anxiety relate to their English learning motivation?

(3) How do the students' foreign language anxiety and English learning motivation relate to their performance in English?

\section{Research Design}

Context of the study. The present research was situated in five state-owned comprehensive universities of various ranks in China, generally representative of the university student population of the country. The teaching and learning of English in all the institutions was predominantly exam-oriented with an enormous focus on reading because all their undergraduate non-English majors had to pass the national College English Test band 4 (CET-4) (a nation-wide English proficiency and exit test which is obligatory for undergraduate non-English majors in most universities and colleges), except the highly prestigious university where the teaching and learning of English was usually more competence-oriented with generally an equal focus on the four basic skills of English because its non-English majors are exempt from CET-4. The lower a university ranked, the more on reading and less on speaking the teaching and learning of English focused in that university. It was the same with the English courses the participants were engaged in when the present study was conducted.

Participants. 1697 (921 female and 776 male) students from five universities of varied ranks in Mainland China participated in the present study. With an average age of 19 and an age range of 16 to 24, the participants came from various disciplines such as business management, civil engineering and environmental engineering, with a majority being first-year students (1169/68.9\%), 481 (28.3\%) being second-year, $43(2.5 \%)$ being third-year and $4(.2 \%)$ fourth-year students. When the present study was conducted, all the participants were enrolled in an English language course in which reading was the dominant activity, followed by speaking and writing.

Instruments. In the present study, the participants were required to fill in the 36-item Foreign Language Anxiety Scale and the 37-item English Learning Motivation Scale, as detailed below.

Foreign Language Classroom Anxiety Scale. The 36-item Foreign Language Classroom Anxiety Scale (FLCAS) used in the present study was adopted from that in Liu and Jackson (2008) which was adapted from the 33-item scale developed by Horwitz et al. (1986). The words language and foreign language appearing in the original 33-item FLCAS were consistently replaced with the word English. Three items were added to reflect the situation in Chinese English classrooms better: "I get tense and nervous when talking to a person whose sex is opposite to mine," "I get tense and nervous when I have to discuss things unfamiliar to me in English," and "I feel overwhelmed by the number of words I have to learn to speak English."

Achieving a Cronbach alpha of .903, the 36-item FLCAS in the present study also measured three dimensions of anxiety: the 12-item fear of negative evaluation (FLCAS1), the 7-item communication apprehension (FLCAS2), and the 2-item test anxiety (FLCAS3). 
English learning motivation Scale. As reviewed earlier, SL/FL learning motivation is a complex construct and involves various learning orientations such as intrinsic and extrinsic, instrumental and integrative orientations. To avoid redundancy and better fit the present situation, the present 37-item English Learning Motivation Scale (ELMS) was designed with reference to several sources (Gao et al., 2004; Noels et al., 2001; Vandergrift, 2005) and aimed to measure seven dimensions which were mutually exclusive: motivation intensity (MI), intrinsic motivation (IntrinM), learning situation (LS), external motivation (ExtM), personal development (PD), going abroad (GA) and academic achievement (AA).

Motivation intensity, also called strength of motivation, was included because students might not really study English hard even though they were motivated to learn the language for various reasons. The 6-item motivation intensity (MI) used in Liu's (2009) study aimed to measure learners' motivation intensity. The 9-item Intrinsic Motivation (IntrinM) was adopted from Schmidt \& Watanabe (2002) and Gao et al. (2004) to measure to what degree learners were intrinsically motivated to learn English. The 5-item Learning Situation, 9-item Personal Development, 3-item Going Abroad, and 1-item Academic Achievement were adopted from Gao et al. (2004) to measure to what extent students were motivated to learn English by their learning situations, personal development, going abroad and academic achievement respectively. The 4-item External Motivation (ExtM) was adopted from Vandergrift's (2005) and Gao et al.'s (2004) studies with repetitious items deleted to explore to what extent learners were externally motivated to learn English.

All the items were placed on a 5-point Likert scale ranging from "Strongly disagree" to "Strongly Agree" with values of 1 to 5 assigned to each descriptor respectively.

Preliminary statistical analyses revealed high internal consistency for the measures (see Table 1).

Table 1. Characteristics of the Instruments $(N=1697)$

\begin{tabular}{lccc}
\hline Instrument & $\begin{array}{c}\text { Number of } \\
\text { Items }\end{array}$ & Reliability & $\begin{array}{c}\text { Mean Item-Total } \\
\text { Correlation }(p=.01)\end{array}$ \\
\hline Foreign Language Classroom Anxiety Scale (FLCAS) & 36 & .903 & .716 \\
Fear of negative evaluation (FLCAS1) & 12 & .899 & .703 \\
Communication apprehension (FLCAS2) & 7 & .831 & .644 \\
Test anxiety (FLCAS3) & 3 & .260 & .1496 \\
English Learning Motivation Scale (ELMS) & 37 & .8113 & .632 \\
Motivation intensity (MI) & 6 & .626 & .3595 \\
Intrinsic motivation (IntrinM) & 9 & .7986 & .483 \\
Learning situation (LS) & 5 & .6564 & .412 \\
External motivation (ExtM) & 4 & .8188 & .641 \\
Personal development (PD) & 9 & .836 & .546 \\
Going abroad (GA) & 3 & .7157 & .537 \\
Academic achievement (AA) & 1 & & \\
\hline Performance in & 3 &
\end{tabular}

Performance in English. Students' scores in the final English language course exam taken by the end of the term were obtained as a global measure of their performance in English. The exam, unanimously, consisted of reading comprehension (40 points), vocabulary and grammar (30 points), and writing (30 points), excluding listening and speaking which were generally assumed to be time-consuming and trouble-making. The questions were set in forms of multiple choices, short answers, short essay writing, and essay writing. Though the degree of difficulty of the final-term exams varied from university to university, the exams were comparable in terms of form, content and difficulty level compatible to the students of a particular university.

Procedure. About 1900 students from 30 intact English language classes at five different universities in Mainland China were invited to complete the questionnaire in Chinese in 20 minutes in a normal class session in the seventeenth week, a week prior to their final course exam. Finally, 1697 collected questionnaires were valid for further statistical analyses; and their scores in the course final exam administered in the $18^{\text {th }}$ week were collected as their performance in English.

Data Analysis. All the survey data were analyzed by SPSS 18. For each measure, the mean, standard deviation, median, mode, and score range were calculated to determine the overall patterns of the students' foreign language anxiety and English learning motivation. Then, the students were categorized into low-, mid-, and high levels of foreign language anxiety and English learning motivation to reveal the within-group patterns. Correlational analyses were run to examine the relationships between the students' foreign language anxiety and English learning motivation. Finally, the relationship between the measured variables and the students' performance in English were explored in terms correlational analyses and multiple regression analyses. 


\section{Results}

\subsection{General patterns of the students' foreign language anxiety and English learning motivation}

5.1.1 Overall pattern

Assessing the general tendency of the students' foreign language anxiety and English learning motivation required the determination of the mean, standard deviation, median, mode, and score range of the FLCAS, the ELMS and their subscales. The researcher adjusted the values assigned to different alternatives of the items expressing confidence in speaking English or little/no motivation. Thus, the total score of the FLCAS revealed the respondent's anxiety in oral English classrooms. Lower FLCAS scores indicated lower anxiety and higher FLCAS scores higher anxiety. The total score of the ELMS revealed the respondent's overall motivation to learn English. Lower ELMS scores suggested lower motivation and higher scores higher motivation.

A total score of more than 144 on the 36-item FLCAS scale implied high anxiety in English classrooms, a total score of 108 to 144 signified moderate anxiety, and a total score of less than 108 indicated little or no anxiety. Likewise, a total score of more than 48 for the 12-item FLCAS1 suggested a strong fear of being negatively evaluated, a total score of 36-48 indicated moderate fear, and a total score of less than 36 reflected little or no fear of being negatively evaluated. For the 7-item FLCAS2, the score ranges for being strongly, moderately apprehensive, and strongly/moderately not apprehensive of speech communication, respectively, were: more than 28, 21-28, and less than 21. The score ranges for a student to be strongly, moderately, and not anxious about English tests, respectively, were: above 8, 6-8, and below 6 for the 2-item FLCAS3.

Similarly, a total score of more than 148 for the 37-item ELMS implied high motivation to learn English, a total score of 111 to 148 suggested moderate motivation, and a total score of less than 111 indicated little or no motivation. Likewise, a total score of more than 24 on the 6-item MI signified great motivation intensity, a total score of 18-24 indicated moderate and a total score of less than 18 reflected little or no motivation intensity. For the 9-item IntrinM and 9-item PD, the score ranges for strong, moderate and little/no intrinsic motivation, and strong, moderate and little/no motivation by personal development, respectively, were: more than 36, 27-36, and less than 27. A total score of more than 20 on the 5-item LS indicated strong motivation by the learning situation, a total score of more than 20 , 15 to 20 and less than 15 suggested moderate and little/no motivation by the learning situation respectively. The score ranges for a student to be strongly, moderately, and not externally motivated, respectively, were: above 16, 12-16, and below 12 for the 4-item ExtM. For the 3-item GA, a score of more than 12, 9-12 and below 9 reflected strong, moderate, and little/no motivation by going abroad respectively. And the score ranges for a student to be strongly, moderately, and not motivated by academic achievement, respectively, were: above 4, 3-4, and below 3 for the 1-item AA.

The results are summarized in Table 2.

Table 2. Statistical Analyses of the FLCAS, the ELMS and Their Subscales $(\mathrm{N}=1697)$

\begin{tabular}{lcrrrrl}
\hline Measure & No. of items & \multicolumn{1}{l}{ M } & SD & Median & Mode & Range \\
\hline FLCAS1 & 12 & 32.88 & 7.37 & 33 & 31 & $12-60$ \\
FLCAS2 & 7 & 20.27 & 3.93 & 20 & 20 & $10-32$ \\
FLCAS3 & 2 & 5.56 & 1.45 & 6 & 6 & $2-10$ \\
FLCAS & 36 & 99.71 & 19.999 & 99 & 93 & $37-172$ \\
MI & 6 & 21.11 & 3.63 & 21 & 22 & $6-30$ \\
IntrinM & 9 & 30.62 & 5.95 & 31 & 30 & $9-45$ \\
LS & 6 & 13.88 & 3.34 & 14 & 12 & $5-25$ \\
ExtM & 5 & 12.25 & 3.6 & 12 & 16 & $4-20$ \\
PD & 9 & 33.61 & 5.52 & 34 & 36 & $9-45$ \\
GA & 3 & 9.38 & 2.54 & 9 & 9 & $3-15$ \\
AA & 1 & 2.83 & 1.02 & 3 & 2 & $1-5$ \\
ELMS & 37 & 123.69 & 15.71 & 123 & 130 & $57-180$ \\
\hline
\end{tabular}

Notes: FLCAS1 = fear of negative evaluation,

FLCAS2 $=$ communication apprehension (FLCAS2); $\quad$ FLCAS3 $=$ test anxiety

FLCAS = Foreign Language Classroom Anxiety Scale; IntrinM = intrinsic motivation

MI = motivation intensity;

ExtM $=$ external motivation

$\mathrm{LS}=$ learning situation; $\mathrm{PD}=$ personal development; $\quad$ GA $=$ going abroad

$\mathrm{AA}=$ academic achievement;

ELMS $=$ English Learning Motivation Scale 
As shown in Table 2, the sample had a mean of 99.71 on the FLCAS (SD =19.999), a median of 99 and mode of 93 , all far below the scale midpoint 108, indicating that only approximately one-third of the students experienced anxiety and the majority were not anxious in their English language classrooms. The FLCAS1 had a mean of 32.88, a median of 33, and a mode of 31; the FLCAS2 had a mean of 20.27, a median and a mode of 20; the FLCAS3 had a mean of 5.56 , a median and a mode of 6 . Generally speaking, all the scores barely exceeded their scale midpoints $(36,21$, and 6 for the FLCAS1, the FLCAS2, and the FLCAS3, respectively). This finding shows that approximately one-third of the participants feared being negatively evaluated, and were apprehensive about both speaking and tests.

Table 2 also shows that the students scored $123.69(\mathrm{SD}=15.71)$ on the ELMS, with a median of 123 and a mode of 130, well above the scale midpoint 111, indicating that the majority respondents were (strongly) motivated to learn English. Meanwhile, the students scored $21.11(\mathrm{SD}=3.63)$ on MI, with a median of 21 and a mode of 22, all exceeding the scale midpoint 18 , suggesting that the majority respondents had a great motivation intensity to learn English. The IntrinM has a mean of 30.62 (SD = 5.95), a median of 31 and mode of 30, above the scale midpoint 27, reflecting that the students were largely integratively motivated to learn English.

LS had a mean of $13.88(\mathrm{SD}=3.34)$, a median of 14 and mode of 12 , below the scale midpoint 15 , meaning the students were generally not motivated by their learning situation. With a mean of $12.25(\mathrm{SD}=3.6)$, a median of 12 and a mode of 16 on ExtM, close to the scale midpoint 12, the students were generally externally motivated to learn English. PD had a mean of $33.61(\mathrm{SD}=5.52)$, a median of 34 and a mode of 36 , well exceeding the scale midpoint 27, suggesting that the students were fairly strongly motivated to learn English by personal development. GA had a mean of $9.38(\mathrm{SD}=2.54)$, a median and mode of 9 , close to the scale midpoint 9 , indicating that the half the participants were motivated to learn English by going abroad. AA had a mean of 2.83 (SD =1.02), a median of 3 and a mode of 2 , below the scale midpoint 3 , meaning that half the respondents were generally not motivated to learn English by academic achievement.

\subsubsection{Within-group pattern}

In addition to the overall patterns of the students' foreign language anxiety and English learning motivation, the present paper also examined the within-group patterns of these measured variables. To do this, the researcher grouped the students into low, mid, and high levels of foreign language anxiety and English learning motivation, with the score range of each level and the number and percentage of students falling into that level reported in Table 3.

Table 3. Number and Percentage of the Students and Score Range at Each FLCAS and ELMS Level

\begin{tabular}{llllllll}
\hline Scale/level & $\begin{array}{l}\text { Low } \\
\text { Number \& } \\
\text { percentage }\end{array}$ & $\begin{array}{l}\text { Score } \\
\text { range }\end{array}$ & $\begin{array}{l}\text { Number \& } \\
\text { percentage }\end{array}$ & $\begin{array}{l}\text { Score } \\
\text { range }\end{array}$ & $\begin{array}{l}\text { Number \& } \\
\text { percentage }\end{array}$ & $\begin{array}{l}\text { Score } \\
\text { range }\end{array}$ & $\begin{array}{l}\text { Raw } \\
\text { score } \\
\text { range }\end{array}$ \\
\hline FLCAS1 & $1177 / 69.4 \%$ & $12 \sim 36$ & $484 / 28.5 \%$ & $37 \sim 48$ & $36 / 2.1 \%$ & $49 \sim 60$ & $12 \sim 60$ \\
FLCAS2 & $1053 / 62.1 \%$ & $10 \sim 21$ & $613 / 36.1 \%$ & $22 \sim 28$ & $31 / 1.8 \%$ & $29 \sim 32$ & $7 \sim 35$ \\
FLCAS3 & $1344 / 79.2 \%$ & $2 \sim 6$ & $310 / 18.3 \%$ & $7 \sim 8$ & $43 / 2.5 \%$ & $9 \sim 10$ & $2 \sim 10$ \\
FLCAS & $1168 / 68.8 \%$ & 37 & $498 / 29.3 \%$ & 109 & $31 / 1.8 \%$ & $145 \sim 172$ & $36 \sim 180$ \\
& & 108 & & 144 & & & \\
MI & $418 / 24.6 \%$ & $6 \sim 18$ & $1001 / 59 \%$ & $19 \sim 24$ & $278 / 16.4 \%$ & $25 \sim 30$ & $6 \sim 30$ \\
IntrinM & $517 / 30.5 \%$ & $9 \sim 27$ & $927 / 54.6 \%$ & $28 \sim 36$ & $253 / 14.9 \%$ & $37 \sim 45$ & $9 \sim 45$ \\
LS & $1201 / 70.8 \%$ & $5 \sim 15$ & $448 / 26.4 \%$ & $16 \sim 20$ & $48 / 2.8 \%$ & $21 \sim 25$ & $5 \sim 25$ \\
ExtM & $890 / 52.4 \%$ & $4 \sim 12$ & $693 / 40.8 \%$ & $13 \sim 16$ & $114 / 6.7 \%$ & $17 \sim 20$ & $4 \sim 20$ \\
PD & $231 / 13.6 \%$ & $9 \sim 27$ & $1091 / 64.3 \%$ & $28 \sim 36$ & $375 / 22.1 \%$ & $37 \sim 45$ & $9 \sim 45$ \\
GA & $866 / 51 \%$ & $3 \sim 9$ & $690 / 40.7 \%$ & $10 \sim 12$ & $141 / 8.3 \%$ & $13 \sim 15$ & $3 \sim 15$ \\
AA & $1188 / 70 \%$ & $1 \sim 3$ & $434 / 25.6 \%$ & $3<\mathrm{x} \leqq 4$ & $75 / 4.4 \%$ & $4<\mathrm{x} \leqq 5$ & $1 \sim 5$ \\
ELMS & $346 / 20.4 \%$ & 57 & $1258 / 74.1 \%$ & 112 & $93 / 5.5 \%$ & $149 \sim 180$ & $37 \sim 185$ \\
& & 111 & & 148 & & & \\
\hline
\end{tabular}

As noted from Table 3, more than $62 \%$ of the respondents were at the low level of foreign language anxiety: they were not afraid of being negatively evaluated, not apprehensive of speech conversations, not anxious about tests, and 
generally not anxious in English language classrooms. Although only $1.8 \%$ to $2.5 \%$ of the participants reported to be highly anxious about negative evaluation, speech communication, tests, and English language classrooms respectively, still around $18.3 \%$ to $36.1 \%$ of them fell into the mid-level group. In particular, more than $30 \%$ of them were moderately or even strongly apprehensive of negative evaluation and speech communication and anxious in English language classrooms. Only about $20 \%$ of them moderately or even highly worried about tests, which might be because tests were often so pervasive in Chinese classrooms, especially in middle school classrooms.

Table 3 also shows that, more than $60 \%$ of the participants reported to have moderate or high motivation intensity, be moderately or even strongly motivated intrinsically or by personal development, and have moderate or even high overall English learning motivation. Around 30\% of them were moderately or highly motivated by their learning situation, around $50 \%$ of them by external motivation or going abroad, and $30 \%$ by academic achievement.

Evidently, most participants were at the low, around $30 \%$ at the mid, and a few at the high level of foreign language anxiety. Nevertheless, the majority were at the mid, around $20 \%$ at the low, and around $15 \%$ or lower at the high level of English learning motivation, except for LS, ExtM, GA and AA. And the differences among students of low-, mid-, and high-level foreign language anxiety and English learning motivation were all statistically significant, as evidenced by the ANOVA results presented in Table 4. Alternatively, students of low-level foreign language anxiety reported to be significantly less anxious in English language classrooms than their mid- and high-level FLA peers. Similarly, students of low-level English learning motivation reported to be significantly less motivated than their mid- and high-level ELM peers.

Table 4. ANOVA Results of Measured Scales

\begin{tabular}{|c|c|c|c|c|c|c|}
\hline \multirow[t]{3}{*}{ Measures } & \multirow[t]{3}{*}{$\mathrm{F}$} & \multirow[t]{3}{*}{$\mathrm{p}$} & \multirow{2}{*}{\multicolumn{3}{|c|}{$\begin{array}{l}\text { Proficiency group (mean) } \\
1=\text { low; } 2=\text { mid; } 3=\text { high }\end{array}$}} & \multirow{3}{*}{$\begin{array}{lc}\text { Location } & \text { of } \\
\text { difference }(p=.05)\end{array}$} \\
\hline & & & & & & \\
\hline & & & 1 & 2 & 3 & \\
\hline FLCAS1 & 1411.95 & .000 & 29.24 & 40.60 & 51.33 & all \\
\hline FLCAS2 & 1753.26 & .000 & 17.82 & 23.99 & 29.87 & all \\
\hline FLCAS3 & 1018.27 & .000 & 5.03 & 7.36 & 9.14 & all \\
\hline FLCAS & 1311.93 & .000 & 89.61 & 120.20 & 152.60 & all \\
\hline MI & 3195.73 & .000 & 16.40 & 21.57 & 26.53 & all \\
\hline IntrinM & 2863.87 & .000 & 23.88 & 31.88 & 39.81 & all \\
\hline LS & 1480.31 & .000 & 12.24 & 17.41 & 22.02 & all \\
\hline ExtM & 2494.947 & .000 & 9.41 & 14.87 & 18.52 & all \\
\hline PD & 2466.85 & .000 & 24.13 & 33.36 & 40.45 & all \\
\hline GA & 2351.64 & .000 & 7.41 & 10.91 & 14.06 & all \\
\hline AA & 2591.56 & .000 & 2.27 & 4 & 5 & all \\
\hline ELMS & 1529.99 & .000 & 102.90 & 126.90 & 157.58 & all \\
\hline
\end{tabular}

\subsection{Correlations between foreign language anxiety and English learning motivation}

To explore the relationship between the students' foreign language anxiety and English learning motivation, correlational analyses between the FLCAS and the ELMS were run, the results of which are reported in Table 5.

Table 5. Correlations between the FLCAS and the ELMS and Their Subscales

\begin{tabular}{lllllllll}
\hline Measure & MI & IntrinM & LS & ExtM & PD & GA & AA & ELMS \\
\hline FLCAS1 & $-.335^{* *}$ & $-.260^{* *}$ & $-.188^{* *}$ & $.260^{* *}$ & -.032 & $-.092^{* *}$ & $-.224^{* *}$ & $-.197^{* *}$ \\
FLCAS2 & $-.320^{* *}$ & $-.270^{* *}$ & $-.188^{* *}$ & $.206^{* *}$ & $-.070^{* *}$ & $-.117^{* *}$ & $-.262^{* *}$ & $-.229^{* *}$ \\
FLCAS3 & -.027 & .031 & $.050^{* *}$ & $.049^{*}$ & -.010 & .038 & .027 & .032 \\
FLCAS & $-.381^{* *}$ & $-.319^{* *}$ & $-.238^{* *}$ & $.255^{* *}$ & $-.071^{* *}$ & $-.133^{* *}$ & $-.285^{* *}$ & $-.266^{* *}$ \\
\hline Note: $*=\mathrm{p}<.05 ;$ & $* *=\mathrm{p}<.01$ & & & & &
\end{tabular}


As shown in Table 5, the FLCAS, the ELMS and their subscales were significantly correlated with one another, except that the FLCAS3 was only significantly positively related to LS $(r=.50, p<.01)$ and ExtM $(r=.049, p<.05)$ but not significantly with the other ELMS scales. The FLCAS, the FLCAS1 and the FLCAS3 were all significantly positively related to $\operatorname{ExtM}(\mathrm{r}=.206 \sim .260, \mathrm{p}<.01)$ but inversely related to the other ELMS scales $(\mathrm{r}=-.381 \sim-.70$, $\mathrm{p}<.01$ ). Alternatively, a more anxious student generally tended to be less motivated to learn English, but was more externally motivated to learn the language.

\subsection{Correlations between the measured variables and performance}

To examine the relationship between the measured variables and the students' performance in English, correlational analyses between the FLCAS, the ELMS and the students' scores in the course final exam were conducted. And the results are summarized in Table 6 .

Table 6. Correlations between the Measured Variables and Performance in English

\begin{tabular}{lllllllllllll}
\hline Measure & FLCAS1 & FLCAS2 & FLCAS3 & FLCAS & MI & IntrinM & LS & ExtM & PD & GA & AA & ELMS \\
\hline P & $-.098^{*}$ & $-.099^{*}$ & $-.068^{*}$ & $-.115^{*}$ & $.170^{*}$ & $.170^{*}$ & $.066^{*}$ & $-.182^{*}$ & -.011 & $.094^{*}$ & $.105^{*}$ & $.094^{*}$ \\
\hline
\end{tabular}

Note: $\mathrm{p}=$ performance; $\quad *=\mathrm{p}<.05$;

As noted in Table 6, all the measured variables except PD were significantly correlated with the students' performance in English: the FLCAS and its three subscales, and ExtM were negatively related to the latter $(\mathrm{r}=-.182$ $\sim-.068, \mathrm{p}<.05)$; and MI, LS, GA, AA and the ELMS were positively related to the latter $(\mathrm{r}=.066 \sim .170, \mathrm{p}<.05)$. Namely, a student who reported to be more anxious or more motivated by external reasons and/or personal development tended to perform worse in the course final exam; but a student who reported to have greater motivation intensity, be more motivated more by intrinsic reasons, the learning situation, going abroad, and/or academic achievement tended to did better in the latter.

\subsection{The regression model}

The results of the correlational analyses discussed previously show numerous bivariate relationships, which failed to indicate the influence of one variable on another. Better clues were provided by multiple regression analyses. A stepwise method was employed in forming regression models. Altogether 7 models were resulted with the change in $\mathrm{R}^{2}$ being all significant: .033 for model $1($ ExtM $)(\mathrm{p}=.000), .024$ for model $2($ ExtM, IntrinM) $(\mathrm{p}=.000), .004$ for model 3 (ExtM, IntrinM, FLCAS3) $(\mathrm{p}=.007), .003$ for model 4 (ExtM, IntrinM, FLCAS3, MI) $(\mathrm{p}=.013), .003$ for model 5 (ExtM, IntrinM, FLCAS3, MI, AA) (p=.017), .003 for model 6 (ExtM, IntrinM, FLCAS3, MI, AA, PD) (p $=.020)$, and .003 for model 7 (ExtM, IntrinM, FLCAS3, MI, AA, PD, GA) $(p=.019)$. Model 7 included seven variables-ExtM, IntrinM, FLCAS3, MI, AA, PD, and GA was the best for the present study. The results are shown in Table 7, which reports coefficients from the regression models, as well as their levels of significance.

Table 7. Regression Coefficients and Significance

\begin{tabular}{lllllllll}
\hline & & ExtM & IntrinM & FLCAS3 & MI & AA & PD & GA \\
\hline Performance & $\beta$ & -.129 & .102 & -.066 & .096 & .049 & -.083 & .063 \\
in English & $t$ & -4.926 & 3.177 & -2.800 & 3.239 & 1.924 & -2.808 & 2.353 \\
& $\mathrm{p}$ & .000 & .002 & .005 & .001 & .055 & .005 & .019 \\
& VIF & 1.245 & 1.876 & 1.008 & 1.589 & 1.182 & 1.577 & 1.323
\end{tabular}

Table 7 shows that all the coefficients were statistically significant $(\mathrm{p}<.01)$. Among the seven included variables, ExtM was the most powerful predictor $(\beta=-.129, t=-4.926)$, followed by IntrinM $(\beta=.102, t=3.177)$, FLCAS3 ( $\beta$ $=-.066, t=-2.800)$, MI $(\beta=.096, t=3.239), \mathrm{AA}(\beta=.049, t=1.924), \mathrm{PD}(\beta=-.083, t=-2.808)$, and $\mathrm{GA}(\beta=.063$, $t=2.353$ ). IntrinM, MI, AA, and GA were positive predictors, while the others were negative ones, consistent with the results of correlation analyses presented in Table 6.

\section{Discussion}

Patterns of the students' foreign language anxiety and English learning motivation. The study shows that the participants reported a medium level of foreign language anxiety, as found in many other studies (Liu, 2006b; Mills et al., 2006; Marcos-Llinás \& Garau, 2009; Spielmann \& Radnofsky, 2001). Moreover, compared with their counterparts in earlier studies (Hao et al., 2004; Liu, 2006b; Liu \& Jackson, 2008), the participants of the present study reported lower level of foreign language anxiety, which might be attributed to the fact that both the China 
Ministry of Education and Chinese people have been paying increasingly more attention to the learning of English in recent years. In many places, students started to learn English in kindergarten, and most in primary school, much earlier than 5-10 years ago when students started English learning in junior high school. Coupled with the fact that it has been increasingly easier to have access to materials in English in both spoken and written forms, the participants might have become more used to the language and thus felt less anxious when speaking it in class, as explained in Liu (2006a) and Tallon (2009).

Similar to their counterparts in diverse SL/FL contexts (Csizér \& Dörynei, 2005; Hao et al., 2004; Kormos \& Csizér, 2010; Liu, 2007; Ushioda, 2008), the participants of the present study reported to be moderately or even highly motivated to learn English. As found in Gao et al.'s (2003a, 2003b, 2004) studies, they reported to be moderately intrinsically and externally motivated, strongly motivated by personal development, moderately motivated by going abroad. Meanwhile, they were not motivated to learn English by their learning situation or academic achievement, unlike those in Gao et al.'s (2003b, 2004) and Dörnyei's (2003), which needs further exploration.

Meanwhile, the present study reveals that most participants were at the low and a few at the high level of foreign language anxiety while the majority were at the mid and around 15\% at the high level of English learning motivation. And the differences among students of low-, mid-, and high-level foreign language anxiety and English learning motivation were all statistically significant. Alternatively, low-anxious students were significantly less anxious in English language classrooms than their mid- and high-anxious peers; so were low-motivated students. Apparently, anxiety and motivation did make a difference among students. Thus, it's important to be able to identify anxious and non-anxious students, motivated and non-motivated students, so that specific strategies can be adopted accordingly to help them better learn the target language, as discussed in the coming section.

Correlations between foreign language anxiety and English learning motivation. As revealed in the present study, foreign language anxiety was significantly correlated with English learning motivation, as found in Hao et al. (2004) and Liu and Huang (2011). For example, a more anxious student generally tended to be less motivated to learn English, but was more externally motivated to learn the language. This might be because anxious students, especially high-anxious students, if not motivated by external reasons such as a better future and a higher mark in exams, would be more inclined to stay in their own world and avoid performing in the target language, especially in evaluative situations, as described in Tobias (1986).

Correlations between the measured variables and performance. The present study also shows that foreign language anxiety was significantly inversely while most ELMS scales were significantly positively correlated with the students' performance in English, as found in numerous existing studies (Csizér \& Dörynei, 2005; Csizér \& Kormos, 2009; Gardner, 1985; Gregersen, 2005; Kormos \& Csizér, 2008; Marcos-Llinás \& Garau, 2009; Ushioda, 2008; Wen, 1997).

Meanwhile, the present study shows that IntrinM, MI, AA, and GA were positive while ExtM, FLCAS3 and PD were powerful negative predictors for the students' performance in English. Namely, intrinsic motivation, motivation intensity, motivation for academic achievement and going abroad facilitated students' performance in English, while external motivation, test anxiety, and motivation for personal development inhibited students' performance in English. This finding, on one hand, further confirms that in previous studies on motivation (Gardner, 1985; Gardner \& Lambert, 1972; Kozaki \& Ross, 2011; Marcos-Llinás \& Garau, 2009; Wen, 1997), on the other hand contradicts with that in other studies of the same nature (Dörnyei, 1994; Hao et al., 2004; Liu \& Huang, 2011). This might be attributed to the fact that only previous studies treated motivation orientations as consisting of only external and integrative or extrinsic and intrinsic motivations (Gardner, 1985; Gardner \& Lambert, 1972; Tremblay \& Gardner, 1995; Warden \& Lin, 2000), which showed that both types of motivations were conducive to language learning and that integrative or intrinsic motivation was more beneficial to long-term language learning. As the motivation construct broke down to more and more smaller subconstructs (Dörnyei, 1994; Oxford \& Shearin, 1994; Schmidt \& Watanabe, 2002; Vandergrift, 2005), the impacts of different types of motivation on language learning began to reveal more specifically, as happened in the present study. Moreover, contrary to Mak's (2011) study of Chinese learners' anxiety, test anxiety revealed to be an important negative predictor to students' performance in English in the present study. This is not surprising in that tests have often been viewed threatening in Chinese contexts. Nevertheless, the contradictory result might also be accounted by the fact the FLCAS3 (test anxiety) has only 2 items within the overall anxiety measure - the FCLAS. All these further justify the need to do more research on language anxiety and motivation in various SL/FL contexts, including the subcomponents of each measure, the impacts of the subcomponents on language learning, the interaction between diverse measures, reasons for and coping strategies to reduce anxiety and enhance motivation, and so on. 


\section{Conclusions and Limitations}

The present research explored the general patterns of Chinese university students' foreign language learning anxiety and motivation and their relationships to the students' performance in English. And the following conclusions can be drawn from the research.

First, some anxiety was reported in English language class as approximately one-third of the participants reported to be anxious in English class, feared being negatively evaluated, and were apprehensive about both speaking and tests. The participants reported to be moderately motivated to learn English: their motivation intensity was high, were largely intrinsically and externally motivated to learn English, fairly strongly motivated to learn English by personal development, moderately motivated to learn English by going abroad, and generally not motivated by their learning situation or academic achievement. Second, more than $60 \%$ of the respondents reported to be at the low level of foreign language anxiety but at the mid level of English learning motivation. The differences among students of low-, mid-, and high-level foreign language anxiety and English learning motivation were all statistically significant. Moreover, the students' foreign language anxiety and English learning motivation were significantly correlated with each other, and the students' performance in English. Finally, external motivation, intrinsic motivation, test anxiety, motivation intensity, academic achievement, personal development and going abroad were powerful predictors of the students' performance in English.

Because of the large sample size, the findings of the present study could be generalizble to other similar SL/FL situations. Even so, due to various constraints, some limitations existed in the present study. Though the sample consisted of students from different years of study and disciplines, the differences in foreign language anxiety and English learning motivation across disciplines and years of study and between male and female students were not examined. Further exploration in these aspects might be more helpful to identify who was more prone to become anxious, who was more motivated to learn English for different reasons, etc., so that teaching and learning could be better monitored to cater to their individual characteristics and needs. In addition, only the overall scores in the final course exam were used to measure the students' performance in English, which could be biased in certain ways. Discrete scores in different parts of the exam could have better reflected a student's performance in English. So could have scores in listening and speaking tests, since speaking and listening were more directly related to the Foreign Language Classroom Anxiety Scale. Moreover, an element of qualitative nature might have rendered more support to the findings, especially to the interaction of foreign language anxiety and motivation and their interactive effect on the learning outcomes. And since correlation analyses alone could not identify the cause or effect of variables, more complicated statistical analyses such as structural equation modeling might be necessary to better understand the interaction of different variables.

\section{Pedagogical Implications}

In spite of the limitations, the findings of the present study have some implications for practical teaching and learning of a SL/FL in classrooms. Although only around a third of the respondents in the present study reported to be moderately or highly anxious in English language class, these students actually needed help most. First of all, both language teachers and learners should be aware of the pervasive existence of foreign language anxiety in class, as suggested in Liu (2006a) and Tsui (1996). As for learners, both Liu (2006a) and Hurd and Xiao (2010) discovered that Chinese language learners preferred self-help over help-seeking strategies, although the majority considered the tutor's role to be of paramount importance. Therefore, language teachers, especially Chinese language teachers, are more responsible to help students become less anxious and more confident in language class. As found in Gregersen (2007), after training, teachers and observers were more accurate in identifying moderate- and high-anxious students in class. Thus, awareness training of SL/FL anxiety is highly recommended to language teachers.

To better students' performance in English, it is necessary for language teachers as well as learners to take measures to alleviate anxiety levels, since anxiety turned out to be a powerful and negative predictor for the students' performance in English. Setting realistic and achievable goals, building a relaxing classroom environment, providing more chances to learners to use the language, encouraging and praising learners often, and so on, are believed to be conducive to reducing anxiety levels (Liu, 2006a; Mak, 2011; Tsui, 1996). As suggested in Mak (2011), all language professionals need to respond to students' affective needs by attempting to provide a secure and comfortable learning atmosphere, free from fear of speaking and conducive to risk taking in the target language.

Meanwhile, Mak's (2011) study revealed that students' negative attitudes towards the language class could contribute to their overall levels of SL/FL anxiety. Thus, the researcher advised language teachers to foster positive attitudes towards the class via open discussions and role-plays in a positive manner, which might help mitigate the effects of anxiety. Abu-Rabia (2004) and Ewald (2007) also found that teachers' supportive attitude helped relieve 
students' anxiety.

Concurrently, once a student' anxiety level is reduced, s/he might become more motivated to learn English, as evidenced by the correlation analyses results in the present study. Since different types of motivation were significantly positively affected students' performance in English, it is necessary to maintain or enhance their motivation to learn the language. Promoting students' awareness of the importance of English, enhancing their self-confidence, fostering their positive attitudes towards English, praising them/giving positive feedback, encouraging them to access English more such as reading English literary works, seeing English films, and making pen pals with international students, etc. may be good ways to enhance students' English learning motivation (Dörnyei, 1994; Liu \& Huang, 2011; Oxford \& Shearin, 1994). With enhanced motivation to learn English, students may have become more willing and active to use the language in various situations and make more efforts to study the language, which may in return result in lower anxiety in English learning.

\section{References}

Abu-Rabia, S. (2004). Teachers' role, learners' gender differences, and FL anxiety among seventh-grade students studying English as a FL. Educational Psychology, 24(5), 711-721. http://dx.doi.org/10.1080/0144341042000263006

Crookes, G., \& Schmidt, R. W. (1991). Motivation: reopening the research agenda. Language Learning, 41(4), 469-512. http://dx.doi.org/10.1111/j.1467-1770.1991.tb00690.x

Csizér, K., \& Dörynei, Z. (2005). The internal structure of language learning motivation and its relationship with language choice and learning effort. The Modern Language Journal, 89, 19-36. http://dx.doi.org/10.1111/j.0026-7902.2005.00263.x

Csizér, K., Kormos, J., \& Sarkadi, Á. (2010). The dynamics of language learning attitudes and motivation: Lessons from an interview study of dyslexic. The Modern Language Journal, 94, 470-487. http://dx.doi.org/10.1111/j.1540-4781.2010.01054.x

Dörnyei, Z. (1994). Motivation and motivating in the foreign language classroom. The Modern Language Journal, $78,273-274$.

Dörnyei, Z. (2003). Attitudes, orientations, and motivations in language learning: Advances in theory, research, and applications. Malden, MA: Blackwell.

Dörnyei, Z., \& Ottó, I. (1998). Motivation in action: A process model of L2 motivation. Working Papers in Applied Linguistics (pp. 173-210). London: Thames Valley University.

Elkhafaifi, H. (2005). Listening comprehension and anxiety in the Arabic language classroom. The Modern Language Journal, 89(2), 206-220. http://dx.doi.org/10.1111/j.1540-4781.2005.00275.x

Ewald, J. D. (2007). Foreign language learning anxiety in upper-level class: Involving students as researchers. Foreign Language Annals, 40(1), 122-142. http://dx.doi.org/10.1111/j.1944-9720.2007.tb02857.x

Frantzen, D., \& Magnan, S. (2005). Anxiety and the true beginner-false beginner dynamic in beginning French and Spanish classes. Foreign Language Annals, 38(2), 171-190. http://dx.doi.org/10.1111/j.1944-9720.2005.tb02483.x

Gao, Y., Zhao, Y., Cheng, Y., \& Zhou, Y. (2003a). The relationship between Chinese college undergraduates English learning motivational intensity and their self identity changes. Foreign Languages and Their Teaching, 170(5), 25-28.

Gao, Y., Zhao, Y., Cheng, Y., \& Zhou, Y. (2003b). The relationship between types of English learning motivation and motivational intensity - a quantitative study on Chinese college undergraduates. Foreign Languages Research, 77(1), 60-64.

Gao, Y., Zhao, Y., Cheng, Y., \& Zhou, Y. (2004). Motivation types of Chinese university undergraduates. Asian Journal of English Language Teaching, 14, 45-64.

Gardner, R. C. (1985). Social psychology and second language learning: The role of attitudes and motivation. London: Edward Arnold.

Gardner, R. C., \& Lambert, W. E. (1972). Attitudes and motivation in second-language learning. Rowley, MA: Newbury House Publishers.

Gregersen, T. (2003). To err is human: A reminder to teachers of language-anxious students. Foreign Language Annals, 36, 25-32. http://dx.doi.org/10.1111/j.1944-9720.2003.tb01929.x 
Gregersen, T. (2005). Nonverbal cues: clues to the detection of foreign language anxiety. Foreign Language Annals, 38, 388-400. http://dx.doi.org/10.1111/j.1944-9720.2005.tb02225.x

Gregersen, T. (2007). Breaking the code of silence: a study of teachers' nonverbal decoding accuracy of foreign language anxiety. Language Teaching Research, 11(2), 209-221. http://dx.doi.org/10.1177/1362168807074607

Gregersen, T., \& Horwitz, E. K. (2002). Language learning and perfectionism: Anxious and non-anxious language learners' reactions to their own oral performance. Modern Language Journal, 86, 562-570. http://dx.doi.org/10.1111/1540-4781.00161

Hao, M., Liu, M., \& Hao, R. P. (2004). An empirical study on anxiety and motivation in English as a foreign language. Asian Journal of English Language Teaching, 14, 89-104.

Horwitz, E. K. (2001). Language anxiety and achievement. Annual Review of Applied Linguistics, 21, 112-126. http://dx.doi.org/10.1017/S0267190501000071

Horwitz, E. K., Horwitz, M. B., \& Cope, J. (1986). Foreign language classroom anxiety. The Modern Language Journal, 70, 125-132. http://dx.doi.org/10.1111/j.1540-4781.1986.tb05256.x

Hurd, S., \& Xiao, J. (2010). Anxiety and affective control among distance language learners in China and the UK. RELC Journal, 41(2), 183-200. http://dx.doi.org/10.1177/0033688210373640

Jenkins, J. (2007). English as a lingua franca: Attitude and identity. Oxford: Oxford University Press.

Kessler, G. (2010). Fluency and anxiety in self-access speaking tasks: the influence of environment. Computer Assisted Language Learning, 23(4), 361-375. http://dx.doi.org/10.1080/09588221.2010.512551

Kitano, K. (2001). Anxiety in the college Japanese language class. Modern Language Journal, 85, 549-566. http://dx.doi.org/10.1111/0026-7902.00125

Kormos, J., \& Csizér, K. (2008). Age-related differences in the motivation of learning English as a foreign language: Attitudes, selves and motivated learning behavior. Language Learning, 58, 327-55. http://dx.doi.org/10.1111/j.1467-9922.2008.00443.x

Kormos, J., \& Csizér, K. (2010). A comparison of the foreign language learning motivation of Hungarian dyslexic and non-dyslexic students. International Journal of Applied Linguistics, 20(2), 232-250. http://dx.doi.org/10.1111/j.1473-4192.2009.00247.x

Kormos, J., Kiddle, T., \& Csizér, K. (2011). Systems of goals, attitudes, and self-related beliefs in second-language-learning motivation. Applied Linguistics, 32(5), 495-516. http://dx.doi.org/10.1093/applin/amr019

Kozaki, Y., \& Ross, S. J. (2011). Contextual dynamics in foreign language learning motivation. Language Learning, 61(4), 1328-1354. http://dx.doi.org/10.1111/j.1467-9922.2011.00638.x

Liu, M. (2006a). Anxiety in EFL classrooms: causes and consequences. TESL Reporter, 39, 13-32.

Liu, M. (2006b). Anxiety in Chinese EFL students at different proficiency levels. System, 34, 301-316. http://dx.doi.org/10.1016/j.system.2006.04.004

Liu, M. (2007). Chinese students' motivation to learn English at the tertiary level. Asian EFL Journal, 9(1), 126-146.

Liu, M. (2009). Reticence and anxiety in oral English lessons. Berne: Peter Lang.

Liu, M., \& Jackson, J. (2008). An exploration of Chinese EFL learners' unwillingness to communicate and foreign language anxiety. The Modern Language Journal, 92, 71-86. http://dx.doi.org/10.1111/j.1540-4781.2008.00687.x

Liu, M., \& Huang, W. (2011). An exploration of foreign language anxiety and English learning motivation. Education Research International, 1, 1-8. http://dx.doi.org/10.1155/2011/493167

MacIntyre, P. D. (1999). Language anxiety: A review of the research for language teachers. In D. J. Young (ed.), Affect in foreign language and second language learning: a practical guide to creating a low-anxiety classroom atmosphere (pp. 24-45). New York: McGraw Hill.

MacIntyre, P. D., \& Gardner, R.C. (1989). Anxiety and second-language learning: Toward a theoretical clarification. Language Learning, 39, 252-275. http://dx.doi.org/10.1111/j.1467-1770.1989.tb00423.x

MacIntyre, P. D., \& Gardner, R. C. (1991). Language anxiety: Its relation to other anxieties and to processing in native and second languages. Language Learning, 41, 513-534. http://dx.doi.org/10.1111/j.1467-1770.1991.tb00691.x 
Mak, B. (2011). An exploration of speaking-in-class anxiety with Chinese ESL learners. System, 39, 202-214. http://dx.doi.org/10.1016/j.system.2011.04.002

Marcos-Llinás, M., \& Garau, M. J. (2009). Effects of language anxiety on three proficiency-level courses of Spanish as a foreign language. Foreign Language Annals, 42(1), 94-111. http://dx.doi.org/10.1111/j.1944-9720.2009.01010.x

Matsuda, S., \& Gobel, P. (2004). Anxiety and predictors of performance in the foreign language classroom. System, 32, 21-36. http://dx.doi.org/10.1016/j.system.2003.08.002

Mills, N., Pajares, F., \& Herron, C. (2006). A reevaluation of the role of anxiety: Self-efficacy, anxiety, and their relation to reading and listening proficiency. Foreign Language Annals, 39(2), 276-295. http://dx.doi.org/10.1111/j.1944-9720.2006.tb02266.x

Mills, N., Pajares, F., \& Herron, C. (2007). Self-efficacy of college intermediate French students: Relation to achievement and motivation. Language Learning, 57, 417-442. http://dx.doi.org/10.1111/j.1467-9922.2007.00421.x

Noels, K. A. (2005). Orientations to learning German: Heritage language background and motivational processes. Canadian Modern Language Review, 62, 285-312.

Noels, K., Clément, R., \& Pelletier, A. G. (2001). Intrinsic, extrinsic, and integrative orientations of French Canadian learners of English. Canadian Modern Language Review, 57, 424-42. http://dx.doi.org/10.3138/cmlr.57.3.424

Oxford, R., \& Shearin, J. (1994). Language learning motivation: Expanding the theoretical framework. Modern Language Journal, 78, 12-27. http://dx.doi.org/10.1111/j.1540-4781.1994.tb02011.x

Ryan, R. M., \& Deci, E. L. (2000). Self-determination theory and the facilitation of intrinsic motivation, social development, and well-being. American Psychologist, 55, 68-78. http://dx.doi.org/10.1037/0003-066X.55.1.68

Schmidt, R., \& Watanabe, Y. (2002). Motivation, strategy use, and pedagogical preferences in foreign language learning. In Z. Dörnyei \& R. Schmidt (eds.), Motivation and second language acquisition (pp. 313-359). Honolulu: University of Hawaii Press.

Spielmann, G., \& Radnofsky, M. (2001). Learning language under tension: New directions from a qualitative study. Modern Language Journal, 8, 259-278. http://dx.doi.org/10.1111/0026-7902.00108

Tallon, M. (2009). Foreign language anxiety and heritage students of Spanish: A quantitative study. Foreign Language Annals, 42(1), 112-137. http://dx.doi.org/10.1111/j.1944-9720.2009.01011.x

Tobias, S. (1986). Anxiety and cognitive processing of instruction. In R. Schwarzer (Ed.), Self-related cognition in anxiety and motivation (pp. 33-54). Hillsdale, NJ: Erlbaum.

Tremblay, P. F., \& Gardner, R. C. (1995). Expanding the motivation construct in language learning. Modern Language Journal, 79, 505-518. http://dx.doi.org/10.1111/j.1540-4781.1995.tb05451.x

Tsui, A. (1996). Reticence and anxiety in second language learning. In K. M. Bailey \& D. Nunan (eds.), Voices from the language classroom (pp. 145-167). Cambridge: Cambridge University Press.

Ushioda, E. (2008). Motivation and good language learners. In C. Griffiths (ed.), Lessons from good language learners (pp.19-34). Cambridge: Cambridge University Press. http://dx.doi.org/10.1017/CBO9780511497667.004

Vandergrift, L. (2005). Relationships among motivation orientations, metacognitive awareness and proficiency in L2 listening. Applied Linguistics, 26, 70-89. http://dx.doi.org/10.1093/applin/amh039

Warden, C. A., \& Lin, H. J. (2000). Existence of integrative motivation in an Asian EFL setting. Foreign Language Annals, 33(5), 535-547. http://dx.doi.org/10.1111/j.1944-9720.2000.tb01997.x

Wen, X. (1997). Motivation and language learning with students of Chinese. Foreign Language Annals, 30(2), 235-251. http://dx.doi.org/10.1111/j.1944-9720.1997.tb02345.x

Wesely, P. M. (2009). The language learning motivation of early adolescent French immersion graduates. Foreign Language Annals, 42(2), 270-286. http://dx.doi.org/10.1111/j.1944-9720.2009.01021.x

Yan, J. X., \& Horwitz, E. K. (2008). Learners' perceptions of how anxiety interacts with personal and instructional factors to influence their achievement in English: A qualitative analysis of EFL learners in China. Language Learning, 58(1), 151-183. http://dx.doi.org/10.1111/j.1467-9922.2007.00437.x 